\title{
EVALUASI PROGRAM DIKLAT MATEMATIKA DENGAN PENDEKATAN PMRI DI BDK PALEMBANG
}

\author{
Oleh : Rudi Hermawan \\ Balai Diklat Keagmaan Palembang \\ rudihermawan67@gmail.com
}

Diterima: 27 Agustus । Disetujui: 24 Oktober I Dipublikasikan: 31 Desember

\begin{abstract}
Abstrak
Penelitan ini bertujuan untuk mengetahui gambaran evaluasi program diklat matematika di BDK Palembang setelah mengikuti pelatihan dengan pendekatan PMRI, yang dilihat dari (1) Bagaimana reaksi dan kepuasan peserta terhadap pelatihan pendekatan PMRI? (2) Bagaimana kemampuan peserta terhadap materi yang dipelajari selama pelatihan? Populasi dan sampel dari penelitian ini adalah: seluruh peserta diklat matematika Madrasah Ibtidaiyah yang terdiri dari 35 orang guru MIN dan MI swasta di wilayah kerja BDK Palembang. Alat pengumpul data adalah Angket terbuka dan tertutup untuk mengukur reaksi dan kepuasan peserta diklat, tes untuk mengukur kemampuan kognitif peserta, serta simulasi di depan kelas. Dari analisis data dapat disimpulkan bahwa dari hasil angket terbuka dan tertutup yang dibagikan kepada peserta sebanyak 35 eksemplar sebagai sampel dapat diketahui $90 \%$ program diklat yang telah dilaksanakan relevan/sesuai dengan kebutuhan guru, $89 \%$ materi yang disajikan juga sesuai dengan kebutuhan dalam melaksanakan tugas guru di sekolah. 90\% peserta pelatihan sangat puas terhadap pelatihan yang diberikan serta membutuhkan kelanjutan dari pelatihan PMRI, dan menyarankan untuk yang akan datang lebih banyak guru yang dilibatkan. Hasil evaluasi terhadap peserta diketahui bahwa seluruh peserta dinyatakan mampu menyelesaikan materi yang diberikan dengan baik, serta mampu mengajarkan materi di depan peserta pelatihan dengan baik.
\end{abstract}

Kata Kunci: Pelatihan pendekatan PMRI, evaluasi program

\begin{abstract}
This research aims to determine the description of the evaluation of the mathematics education and training program at BDK Palembang after participating in training with the PMRI approach, as seen from (1) How did the participants react and satisfy the PMRI approach training? (2) How are the participants' abilities regarding the material learned during the training? The population and sample of this study were: all mathematics training participants at Madrasah Ibtidaiyah consisting of 35 private MIN and MI teachers in the working area of BDK Palembang. Data collection tools are open and closed questionnaires to measure the reactions and satisfaction of training participants, tests to measure participants' cognitive abilities, and simulations in front of the class. From the data analysis it can be concluded that from the results of open and closed questionnaires distributed to participants as many as 35 copies as a sample, it can be seen that $90 \%$ of the training programs that have been implemented are relevant / in accordance with the needs of the teacher, $89 \%$ of the material presented is also in accordance with the needs in carrying out teacher duties in school. 90\% of the training participants were very satisfied with the training provided and needed a continuation of the PMRI training, and suggested that more teachers would be involved in the future. The results of the evaluation of the participants indicated that all participants were declared capable of completing the given material well, and were able to teach the material well in front of the training participants.
\end{abstract}

Keywords: PMRI approach training, program evaluation

This work is licensed under a Creative Commons Attribution-NonCommercial 4.0 International License 


\section{PENDAHULUAN}

\section{Latar Belakang}

Dalam rangka peningkatan mutu pendidikan, upaya peningkatan kompetensi guru yang merupakan ujung tombak dalam proses pendidikan merupakan satu aspek substantive manajemen pendidikan yang harus diwujudkan melalui berbagai program operasional. Dengan peningkatan kompetensi tersebut diharapkan guru menjadi kompeten dalam mengelola proses belajar-mengajar di satuan pendidikannya. Guru yang berkompeten akan dapat merubah paradigma pendidikan dari pembelajaran yang berpusat pada guru (Teacher Centre) ke pembelajaran yang berpusat pada siswa (Student Centre). Perubahan paradigma ini diharapkan dapat menciptakan suasana yang menyenangkan dan terciptanya aktifitas serta kreativitas dari peserta didik yang pada akhirnya menunjang pencapaian tujuan pembelajaran yang efektif. Tetapi sebaliknya guru yang tidak kompeten akan tetap mendominasi kelas dengan melakukan pembelajaran yang berpusat pada guru (Teacher Centre). Akibatnya guru melaksanakan pembelajaran dengan pendekatan pembelajaran yang monoton dan sulit menerima pendekatan pembelajaran yang baru.

Salah satu upaya untuk meningkatkan kompetensi guru agar menjadi guru yang kompeten adalah dengan melakukan Pendidikan dan Pelatihan (Diklat). Balai Diklat Keagamaan Palembang adalah salah satu lembaga pelatihan dengan tujuan meningkatkan kompetensi pegawai Kementerian Agama termasuk guru. Pada bulan April tahun 2019, Balai Diklat Keagamaan Palembang mengadakan kegiatan pelatihan guru matematika Madrasah Ibtidaiyah (MI). Pendekatan pembelajaran yang dilaksanakan pada pelatihan guru matematika tingkat MI ini yaitu Pendekatan Matematika Realistik Indonesia (PMRI). Pelatihan dengan pendekatan PMRI diikuti oleh 35 guru matematika dari wilayah kerja BDK Palembang.

Berdasarkan hal di atas peneliti tertarik melakukan evaluasi program pelatihan matematika MI dengan tujuan untuk mengetahui gambaran pelatihan guru matematika MI di BDK palembang.

\section{Identifikasi Masalah}

Berdasarkan latar belakang di atas di identifikasikan beberapa masalah :

a. Pembelajaran yang masih berpusat pada guru (Teacher Centre)

b. Kesulitan guru memahami pendekatan pembelajaran yang baru

c. Pendekatan pembelajaran yang monoton

\section{Rumusan Masalah}

Adapun rumusan masalah pada penelitian ini adalah :

a. Bagaimana reaksi dan kepuasan peserta terhadap pelatihan PMRI ?

b. Bagaimana kemampuan peserta terhadap materi yang dipelajari selama pelatihan?

\section{Tujuan Penelitian}

Tujuan dari kegiatan pelatihan guru mata pelajaran matematika ini adalah:

a. Untuk mengetahui reaksi dan kepuasan peserta terhadap pelatihan PMRI

b. Untuk mengetahui apakah peserta telah mengerti terhadap apa yang dipelajari selama pelatihan

\section{Kajian Teori}




\section{Evaluasi Program}

Suatu program perlu dievaluasi agar diketahui tingkat keberhasilannya. Hasil evaluasi akan menentukan tentang keberlangsungan suatu program. Jika hasil evaluasi baik, maka program dapat terus dilaksanakan dengan perbaikan. Sebaliknya jika hasilnya kurang baik maka program tersebut dapat di perbaiki atau bahkan ditiadakan. Jadi dapat dikatakan bahwa evaluasi ini menjadi bahan bagi penyelenggara untuk memutuskan tindakan tentang suatu program. Provus memandang evaluasi dari segi kesesuaian program dengan penampilan standar: "Evaluation is the comparison of performance to some standard to determine whether discrepancies existed" (Provus, 1971). Scriven memandang evaluasi sebagai metode untuk menilai kegunaan dan kemanfaatan suatu program: Evaluation as the assessment of worth and merit" (Scriven, 1967; Glass, 1969). Stake mengatakan bahwa apabila kita menilai suatu program pendidikan kita melakukan perbandingan yang relative antara satu program dengan yang lain, atau perbandingan yang absolut (satu program dengan standar). Sedangkan Stufflebeam memandang evaluasi sebagai suatu proses untuk mengungkap, mencari dan menganalisis, dan menyajikan untuk pembuatan keputusan: "Evaluation is the process of delineating, obtaining, and providing information for decision making" (Stufflebeam, 1971). "Evaluation is the systematic investigation of the worth or merits of Ilma, Efek Potensian Pelatihan PMRI Terhadap Guru-guru Matematika some object" (Joint Committee, 1981).

Sedangkan Dunn mengatakan evaluasi sebagai metode analisis kebijakan: Evaluation is the policyanalitical method used to produce information about the value or worth of past and/or future courses of action" Menurut Rutman (1984), evaluasi program adalah penerapan metode- metode ilmiah untuk mengukur implementasi dan hasil program untuk pengambilan keputusan. Sedangkan Brinkerhoff (1983), menyatakan bahwa evaluasi program adalah: (1) proses menentukan sejauh mana tujuan dan sasaran program telah terealisasi, (2) memberikan informasi untuk pengambilan keputusan, (3) perbandingan kinerja dengan patokanpatokan tertentu untuk menentukan apakah terdapat kesenjangan, (4) penilaian tentang harga dan kualitas, dan (5) investigasi sistematis mengenai nilai atau kualitas suatu objek.

\section{Pembelajaran PMRI}

Pembelajaran yang diklakukan selama ini hanya berorientasi pada target penguasaan materi saja, sehingga pembelajaran yang demikian akan kurang bermakna. Hal ini sesuai dengan kenyataan bahwa pembelajaran yang berorientasi pada target penguasaan materi telah terbukti berhasil dalam kompetensi hanya pada pengetahuan “ mengingat " jangka pendek, tetapi tidak berhasil/gagal dalam membekali peserta didik melakukan pemecahan masalah dalam kehidupan jangka panjang.

Pada pembelajaran matematika, isuisu tentang kekurangberhasilan pembelajaran matematika telah banyak dikemukakan oleh para pakar. RME (Realistic Mathematics Education) banyak ditentukan oleh pandangan Freudenthal tentang matematika. Dua pandangan penting beliau adalah mathematics must be connected to reality and mathematics as human activity'. Pertama, matematika harus dekat terhadap siswa dan harus relevan dengan situasi kehidupan sehari- hari siswa. 
Kedua, ia menekankan bahwa matematika sebagai aktivitas manusia, sehingga siswa harus diberi kesempatan untuk belajar melakukan aktivitas semua topik dalam matematika.

Di Indonesia sejak tahun 2004 RME diadaptasi, dimana disesuaikan dengan konteks Indonesia dengan nama PMRI. Horizontal dan vertikal merupakan dua tipe matematisasi secara ekplisit . Pada horizontal, siswa menggunakan matematika sehingga dapat membantu mereka mengorganisasi dan menyelesaikan suatu masalah yang ada pada suatu situasi nyata. Sebaliknya, pada tipe vertikal, dilakukan proses pengorganisasian kembali menggunakan matematika itu sendiri. Implementasi PMRI

Menurut Zulkardi (2002) model pembelajaran berdasarkan pendekatan realistik, model tersebut harus merepresentasikan karakteristik PMRI baik pada tujuan, materi, metode dan evaluasi. Tujuan haruslah memuat tiga tahap tujuan dalam PMRI: tahap rendah (procedural), Tahap menengah (pemecahan masalah), dan tahap tinggi (matematisasi dan generalisasi). Dua tujuan terakhir, menekankan pada kemampuan berargumentasi, berkomunikasi dan pembentukan sikap kritis. Pada situasi ini mereka mempunyai kesempatan untuk bekerja, berfikir dan berkomunikasi tentang matematika. Peranan guru hanya sebatas fasilitator atau pembimbing. Materi evaluasi harus dibuat dalam bentuk ópen question' yang memancing siswa untuk menjawab secara bebas dan menggunakan beragam strategi atau beragam jawaban atau free productions. Evaluasi harus mencakup formatif dan sumatif.

\section{METODE PENELITIAN}

\section{Model Evaluasi}

Evaluasi program yang dugunakan dalam penelitian ini adalah evaluasi model kirkpatrick. Evaluasi model kirkpatrick ini terdiri dari empat tahap (Kirkpatrick, 2006). Setiap tahap penting dan mempunyai pengaruh pada tahap berikutnya. Empat tahap untuk menentukan efektifitas program adalah: Tahap 1: Reaction (Reaksi); Tahap 2: Learning (Belajar); Tahap 3: Behavior (Tingkah Laku); Tahap 4: Results (Hasil);

a. Reaksi

Evaluasi pada tahap ini mengukur bagaimana reaksi peserta dalam program pelatihan. Tahap ini disebut juga kepuasan peserta (customer satisfaction).

b. Belajar

Evaluasi pada tahap ini menentukan peningkatan pengetahuan, kemampuan, dan keahlian peserta tentang materi pelatihan.

c. Tingkah Laku

Evaluasi pada tahap ini mengukur perubahan sikap dan perilaku peserta setelah mengikuti pelatihan, dimana hasil dari pelatihan diterapkan di sekolah masing-masing.

d. Hasil

Evaluasi pada tahap ini dapat didefinisikan sebagai hasil akhir yang terjadi dari usaha peserta yang terlibat dalam pelatihan.

Dalam penelitian ini, hanya

menggunakan dua tahap yang pertama.

\section{Populasi dan Sampel}

Populasi : Seluruh peserta Pelatihan PMRI yang terdiri dari 35 orang guru dari wilayah kerja BDK Palembang

Sampel : Seluruh peserta Pelatihan PMRI yang terdiri dari 35 orang guru dari wilayah kerja BDK Palembang 


\section{Teknik Pengumpulan Data}

a. Angket untuk mengukur reaksi dan kepuasan peserta pelatihan PMRI.

b. Observasi untuk melihat kemampuan mengajar peserta pada saat simulasi secara kelompok di depan peserta pelatihan lainnya. c. Tes untuk mengukur kemampuan pengetahuan peserta pelatihan.

\section{Teknik Analisis Data}

Angket

Data angket dianalisis dengan menetapkan skor persepsi peserta pelatihan, setiap pertanyaan/pernyataan terdiri dari 5 alternatif jawaban, yaitu sangat setuju (SS), setuju (S), tidak tahu (R), tidak setuju (TS), dan sangat tidak setuju (STS). Masing- masing diberi skor dengan menggunakan skala Likert.

\section{Observasi}

Untuk melihat kemampuan mengajar peserta pada saat simulasi secara kelompok di depan peserta pelatihan lainnya yang diperoleh melalui lembar observasi. Skor yang digunakan untuk mengolah data observasi adalah skala angka 0 sampai dengan 4. Skor 4 jika 4 dekriptor muncul, skor 3 jika hanya 3 deskriptor muncul, skor 2 jika hanya 2 deskriptor muncul, skor 1 jika hanya 1 deskriptor muncul dan 0 dan skor jika tak satupun deskriptor muncul. Skor maksimum adalah 16 dan skor minimum 0. Observasi juga untuk melihat perubahan sikap guru dalam mengajar.

Tes

Untuk mengukur kemampuan pengetahuan

peserta pelatihan. Langkah-langkah yang

dilakukan :

1. membuat kunci jawaban dan skor pada

setiap jawaban soal

2. memeriksa jawaban siswa (tes)
3. menjumlahkan skor semua jawaban dari tiap soal

4. mengkonversikan skor ke dalam nilai siswa dalam rentang 0-100

5. mengkonversikan nilai akhir siswa ke dalam data kualitatif untuk menentukan kategori hasil belajar

\section{TEMUAN DAN PEMBAHASAN}

\section{Temuan}

Tahap 1: Reaction (Reaksi)

Aspek yang dinilai dari program ini adalah untuk mengetahui reaksi dan kepuasan peserta terhadap pelatihan PMRI. Dari hasil kuesioner yang dibagikan kepada peserta sebanyak 35 eksemplar sebagai sampel dapat diketahui 90 $\%$ menyatakan program pelatihan yang telah dilaksanakan relevan/sesuai dengan kebutuhan guru, $89 \%$ materi yang disajikan juga sesuai dengan kebutuhan dalam melaksanakan tugas guru di sekolah, $90 \%$ peserta pelatihan sangat puas terhadap pelatihan yang diberikan serta membutuhkan kelanjutan dari pelatihan dengan pendekatan PMRI.

Tahap 2: Learning (Belajar)

Untuk menentukan tingkat keberhasilan peserta pelatihan, maka penanggung jawab program akademik telah melaksanakan penilaian melalui test dan observasi tentang penguasaan materi yang mencakup ranah sikap, pengetahuan dan ketrampilan peserta selama mengikuti program Pelatihan dengan mengacu pada kategori yang telah ditetapkan yaitu: 
Tabel 1. Kategori nilai tes

\begin{tabular}{|c|c|}
\hline Rentang Nilai & Kategori \\
\hline $85-100$ & Sangat Baik \\
\hline $75-84$ & Baik \\
\hline $65-74$ & Cukup Baik \\
\hline $55-64$ & Kurang Baik \\
\hline$\leq 55$ & Sangat Kurang Baik \\
\hline
\end{tabular}

Hasil tes rata-rata peserta pelatihan adalah 78 yang termasuk kategori baik.

\section{Pembahasan}

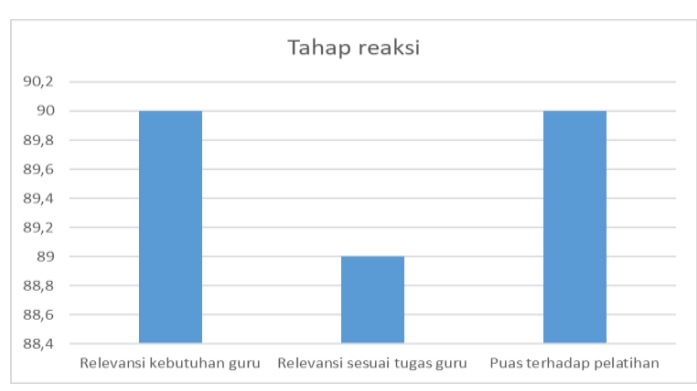

Gambar 1. Reaksi dan kepuasan peserta terhadap pelatihan

Pada tahap rekasi seperti terlihat gambar di atas menunjukan bahwa peserta pelatihan puas dengan materi PMRI sesuai dengan apa yang diharapkannya sehingga termotivasi untuk melaksanakan apa yang sudah diperoleh dalam pelatihan. Sedangkan evaluasi program non akademik adalah untuk mengetahui tanggapan peserta tentang kegiatan program pelatihan, fasilitas pelatihan, fasilitas akomodasi, konsumsi, dan tentang panitia penyelenggara pelatihan. Adapun hasil Evaluasi program non akademik secara umum baik. Namun masih perlu ditingkatkan untuk masa yang akan datang.

Pada tahap belajar yang diukur dengan tes menunjukan hasil nilai tes dengan kategori baik. Dalam hal ini peserta mampu memahami materi PMRI, serta mampu mengajarkannya di depan peserta pelatihan.
Sebagai upaya mengetahui tingkat kemampuan peserta maka dilakukan evaluasi guna mengukur tingkat kemampuan peserta setelah mengikuti program pelatihan PMRI di BDK Palembang yang pada akhirnya dapat diukur sejauh mana hasil penyerapan peserta terhadap materi yang telah disajikan. Hasil akhirnya diharapkan adanya peningkatan kemampuan, aktivitas, dan minat siswa dalam matematika setelah diberikan pembelajaran PMRI oleh guru yang mengikuti pelatihan. Dari hasil evaluasi program akademik dapat diketahui bahwa seluruh peserta dinyatakan mampu menyelesaikan materi yang diberikan dengan baik, serta mampu mengajarkan materi di depan peserta pelatihan sesuai dengan karakteristik dan prinsip PMRI.

\section{PENUTUP}

\section{Simpulan}

a. Dari hasil angket tertutup yang dibagikan kepada peserta sebanyak 35 eksemplar sebagai sampel dapat diketahui $90 \%$ program pelatihan yang telah dilaksanakan relevan/sesuai dengan kebutuhan guru, 89 $\%$ materi yang disajikan juga sesuai dengan kebutuhan dalam melaksanakan tugas guru di sekolah, $90 \%$ peserta pelatihan sangat puas terhadap pelatihan yang diberikan serta membutuhkan kelanjutan dari pelatihan PMRI,

b. Dari hasil tes yang diberikan terhadap peserta diketahui bahwa seluruh peserta dinyatakan mampu menyelesaikan materi yang diberikan dengan baik, serta mampu mengajarkan materi di depan peserta pelatihan dengan baik.

\section{Rekomendasi}

Semua peserta menyarankan agar yang akan datang lebih banyak guru yang dilibatkan. 


\section{DAFTAR PUSTAKA}

Joint Committee on Standards for Educational Evaluation. 1981. Standards for Evaluation of Educational Program, Project, and Materials. New York: McGraw-Hill.

Kirkpatrick, D.L. \& Kirkpatrick, J.D. 2006. Evaluating Training Program. San Fransisco: Berrett- Koehler Publishers,Inc.

Provus. 1971. The Discrepancy Evaluation Model. Dari

http://Scholar.lib.vt.edu/ Ejournals /JTE/V2N2/html/house.html

Rutman, L. 1984. Planning Useful Evaluation: Evaluability Assessment. Newbury Park, CA: Sage Publisher

Scriven, M . The Methodology of Evaluation. 1967. Dalam R Tyler (ed), Perspective of

Curriculum Evaluation. AERA Monobraph Series on Curriculum Evaluation (No.1) Skokie, IL :

Rand Mc Nally.

Stufflebeam, Daniel L. et al. 1971. Educational Evaluation and Decision Making. Itaca, Illinois: F. E. Peacock.

Undang-Undang Republik Indonesia Nomor 20 Tahun 2003 tentang Sistem Pendidikan Nasional.

Zulkardi, 2002 . Developing A Learning Environment On Realistic Mathematics Education For Indonesian Student Teachers. The Nederlands. 